\title{
BMJ Open Carers' experience of using assistive technology for dementia care at home: a qualitative study
}

\author{
Vimal Sriram (D), Crispin Jenkinson, Michele Peters
}

To cite: Sriram V, Jenkinson C, Peters M. Carers' experience of using assistive technology for dementia care at home: a qualitative study. BMJ Open 2020;10:e034460. doi:10.1136/ bmjopen-2019-034460

- Prepublication history and additional material for this paper are available online. To view these files, please visit the journal online (http://dx.doi. org/10.1136/bmjopen-2019034460).

Received 20 September 2019 Revised 24 February 2020 Accepted 27 February 2020

\section{Check for updates}

(C) Author(s) (or their employer(s)) 2020. Re-use permitted under CC BY-NC. No commercial re-use. See rights and permissions. Published by BMJ.

Nuffield Department of Population Health, University of Oxford, Oxford, UK

Correspondence to

Vimal Sriram;

vimal.sriram@dph.ox.ac.uk

\section{ABSTRACT}

Objective Assistive technology (AT) can help carers (family, friends and neighbours) and people with dementia to stay well and safely at home. There are important gaps in what we know about experience of using AT from the perspective of carers of persons with dementia. This study investigates carers' experience of using AT in supporting and caring for persons with dementia who live at home. Design Qualitative phenomenological study with semistructured interviews to achieve data saturation and thematic analysis to identify key themes.

Setting Community-based within the UK.

Participants Twenty-three (14 women, 9 men) adult carers of persons with dementia who have used at least one AT device.

Results All participants reported benefiting to varying degrees from using AT. There were 5 themes and 18 subthemes that highlighted reasons for using AT and use of AT over time. Providing care for a person with dementia, motivation for using AT, changes to roles and routines, carer knowledge and skills for using AT and social, environmental and ethical considerations were the main themes. This study showed that AT can provide reassurance and support for carers of persons with dementia but there are difficulties with acquiring and continued use of AT as dementia progresses.

Conclusions Carers consider AT as an adjunct to care they provided in caring for a person with dementia. Use of AT should be considered in the personal, social and environmental context of persons with dementia and their carers. Further research and policy interventions are needed to address best use of resources and guidance on data sharing and data protection while using AT.

\section{INTRODUCTION}

Dementia is increasingly prevalent and is a public health priority. ${ }^{12}$ There are an estimated 46.8 million people with dementia globally and the number is likely to double by $2035 .^{34}$ Much of the care for persons with dementia living at home is provided by informal carers. ${ }^{5}$ In the UK, there are over 700000 informal carers for persons with dementia. ${ }^{6}$ The value of time given by informal carers to persons with dementia is estimated to be approximately $£ 12.4$ billion a year for the UK, ${ }^{67}$ and the global economic cost of dementia is estimated to be over US\$604 billion. ${ }^{8}$

\section{Strengths and limitations of this study}

This study recruited participants from across the UK giving a broad geographical perspective.

- The study adopted a purposeful sampling strategy to identify people with a range of characteristics to capture diverse data relevant to the research question.

- Semi-structured interviews were conducted to provide rich data that allowed in-depth understanding of carers' experiences of using assistive technology.

- The participants were recruited through voluntary participation in research databases and potentially may not be representative.

An informal carer is 'someone who, without payment, provides help and support to a partner, child, relative, friend or neighbour, who could not manage without their help'.9 Caring for a person with dementia can be viewed through a biopsychosocial model. ${ }^{10} 11$ Carers can have either a positive or negative influence on the health and well-being of a person with dementia. Contextual and environmental factors affect functioning, health and long-term outcomes for a person with dementia as well as their carer. ${ }^{12}$ Stretched health and social care resources necessitate alternative and innovative ways of providing care for someone with dementia. ${ }^{13}$ Assistive technology (AT) has been suggested as a means to support persons with dementia to stay independent and remain in the community and assist carers by providing them with a sense of safety, reassurance and communication with the person with dementia. ${ }^{14-16}$ AT can be defined as 'any item, piece of equipment, product or system that is used to increase, maintain or improve the functional capabilities and independence of people with cognitive, physical or communication difficulties', ${ }^{17}$ for example, products such as talking clocks, electronic medication dispensers, robotic vacuum cleaners, smart gas metres, audio books, navigation systems, falls and motion detectors and door exit alarms. ${ }^{17-19}$ 
AT may assist carers to address the increased level of responsibility they face while caring for a person with dementia. ${ }^{20}$ Carers could be using the AT together with the person with dementia (such as safety alarms); they could be using the AT by themselves (such as remote monitoring technologies) and/or the person with dementia may be using the AT independently (such as smart phones).

Living at home brings with it a sense of security and freedom ${ }^{21} 22$ and people with dementia and their families will largely strive for them to live at home for as long as possible. ${ }^{23}$ With technological advances, in the Internet of Things (extension of internet connectivity into physical devices and everyday objects) ${ }^{24}$ and artificial intelligence, AT will become more personalised to individual needs and user requirements. ${ }^{25}$ However, despite several recommendations carers are still not placed at the centre of design, prescription and use of AT for someone with dementia. ${ }^{196}$ A recent systematic review ${ }^{19}$ found that there was no consistency in describing or classifying AT for use in dementia and that carers often struggle due to a lack of support for using AT, AT not meeting the needs of individual carers and design flaws in the AT. The review recommended that carers along with persons with dementia need to be involved in the design and testing of AT and carer experiences with using AT should be an area of further research. Knowledge of carers' experience with AT will provide information to those who procure health services, health professionals, charities and industry partners developing new AT regarding what AT carers use and prefer; how they use it and how it helps them. ${ }^{27}$ This in turn would enable tailored advice and delivery of better care, information and support which subsequently may improve carer outcomes and quality of life. This study aimed to explore the perceptions and experiences of using AT among carers of persons with dementia living at home in the UK.

\section{Ethics}

All volunteers were provided with a participant information sheet that listed a range of AT devices (online supplementary file 1) and those who expressed an interest in the study were reminded of these prior to the interview. All recruited participants provided informed written consent (online supplementary file 2) prior to the interview. All participants are identified by a participant number within this paper.

\section{METHODS}

\section{Patient and public involvement}

The interview topic guide was pilot tested on two carers of persons with dementia and refined based on their input. This study is part of a larger research project which has a patient and public advisory group that meets twice a year. The group consists of two carers of persons with dementia and a person with dementia (all living in England). The first meeting of this group was held after interviews had commenced, however the interview topic guide (box 1) was shared with this group for their comments and input; and on review was agreed as enabling participants to answer
Box 1 Carers' experience of assistive technology use in dementia-interview topic guide

Pre-interview:

Participant to re-receive the information sheet and asked to read it through. Participant will be given a brief introduction to the research that includes a description of assistive technology (AT).

- Show university card for ID of researcher and introduce self.

- Participant to be told what will happen during the interview process and reminded that the interview will also be audio recorded.

- Participant to be told that an anonymised transcript will be made from the audio recording.

- Participant to be told the method of analysis and reminded that they will remain anonymous, and that their data will be confidential.

- Participant given time to ask questions.

- Participant will be asked to sign two copies of the consent form, one of which is to be retained by the researcher.

Questions:

Background:

1. Can you tell me a bit about yourself and your current situation and living arrangements? - You have the option of not providing this information if you do not wish to.

2. How long have you been helping, looking after or caring for (person with dementia)? How did it start?

3. How is your day to day life affected by helping, looking after or caring for (person with dementia)? What tasks do you help or support them with?

4. How is your health generally?

5. How has your caring role changed since you first took on the role? In what way?

6. What support, if any, do you receive from other people?

7. What would help you on a day-to-day basis? This could be something (or many things) to support your own health and well-being, or to help you care for (person with dementia)?

8. What tasks that you help or support (person with dementia) with do you find challenging?

9. Are you aware of the Care Act 2014? Have you had a carer's assessment? Have you received any support to help your caring needs?

Use of AT:

As you know we are particularly interested in your experiences of AT use for (person with dementia), give examples of AT.

1. What do you think are helpful and unhelpful about the use of ATs?

2. What AT do you use with (person with dementia)? Can you tell me why these types of ATs were chosen and used? How do you and/or (person with dementia) use AT?

3. What is your main purpose for using the AT (ask for each type of AT)? Are there any other purposes?

4. What was particularly helpful or unhelpful about the use of each AT? If you are using multiple types of AT, is there one that is more helpful than others (and if so why)?

5. Do you think using this AT helps/helped you in caring for (person with dementia)?

6. What would you do to support (person with dementia) if this AT was not available?

7. If you have used an AT before and no longer are using it, what do you think prevented you or (person with dementia) from using it?

Experience of using AT:

1. Can you tell me more about your experiences with this (these) AT(s)?

2. Can you tell me your views or experiences regarding the use of or non-use of AT as (person with dementia) dementia progresses?

3. How do you feel about using AT to support (person with dementia)?

Continued 


\section{Box 1 Continued}

And yourself?

4. Do you feel the AT is integrated in your daily life/help/care that you provide for (person with dementia)?

5. What support have you needed to use the AT? Where did you get the support from?

6. How has use of AT impacted on your well-being/quality of life? Is there anything else you would like to add about your caregiving experience or AT?

the research questions for this study. This group has also committed to support dissemination of study results to other patient involvement groups and their wider networks.

\section{Study design}

This study used hermeneutic phenomenology $y^{28-30}$ as a qualitative methodology ${ }^{31}{ }^{32}$ with thematic analysis ${ }^{33-36}$ of responses to semi-structured interview questions. Hermeneutic phenomenology deals with the way in which the world is understood and interpreted in relation to cultural, social and historical contexts. The method was designed to interpret meaning not just of stated facts but of understanding the lived experience in context and to then consider important themes and characteristics of the expressed facts. Lindseth $e t a l^{87}$ use the example of a chair to illustrate this-a chair could be a familiar concept, as a place to sit on, for some chairs are where people are enthroned and for others such as in a university, a chair could be a position held for teaching or research. Thus, lived experience must be interpreted from the text. Using this method allowed us to explore the complexity and context aligned nature ${ }^{3839}$ of carers' experiences of using AT in caring for a person with dementia living at home. We have been guided by the COnsolidated criteria for REporting Qualitative research (COREQ) to report this study. ${ }^{40}$

\section{Recruitment}

Participants were recruited from website-based databases: (1) Join Dementia Research ${ }^{41}$ delivered in partnership with the National Institute for Health Research, Alzheimer's Scotland, Alzheimer's Research UK and Alzheimer's Society, which enables people wishing to volunteer for research to register an interest to be matched with suitable research studies and (2) OxDARE, ${ }^{42}$ a database that engages the local community in Oxfordshire in educational events and research opportunities in dementia. Participants were carers of persons with dementia based in the UK willing to be contacted by researchers through these websites. The website allows researchers to identify appropriate volunteers. For this study, the inclusion criteria were: adult carers-family, friends or neighbours-providing at least 10 hours of care (eg, shopping, leisure, personal care, finance) per week to a person with dementia who lives in their own home, with the carer living together with or away from the person with dementia. Carers should have used at least one AT device at home in the previous year and be able to speak English.
An email with the participant information sheet was sent to volunteers who met the criteria. From those volunteers who replied expressing an interest in participating, a purposive sample of participants reflecting variations in gender, age, ethnicity, living arrangements, rurality and relationship with persons with dementia were selected. The recruitment commenced in August 2018 and the final interview was completed in June 2019.

\section{Data collection}

Semi-structured interviews were conducted face to face (at the participant's own home/at the researcher's office) or over the telephone considering the participant's geographical location and preference. The interview used openended questions informed by an earlier systematic review ${ }^{19}$ and confirmed as meeting the needs for answering the research questions by the patient and public advisory group. The questions explored the participants' experiences of caring for someone with dementia, their experience of using AT and the impact of AT on daily life (box 1). The background of the interviewer as an occupational therapist and consequent interest in the research topic was discussed with participants when it came up. The participants were not known to the interviewer or the other authors before recruitment and trust in the interviewer was built by establishing rapport with the participants. Interviews lasted between 30 and $55 \mathrm{~min}$, were audio recorded and later transcribed verbatim with names of participants, the person being cared for and any towns/cities mentioned in the interviews pseudonymised to ensure confidentiality.

\section{Data analysis}

The data were analysed using NVivo V.12. The process followed was inspired by the method by Lindseth and Norberg. ${ }^{31}{ }^{37}$ VS listened to each of the interviews (naïve understanding) and transcribed them with assistance from a professional transcriber (first step). This was followed by identifying 'meaning units' that captured carers' experience of caring and using AT (structural analysis). These groups of statements from the transcribed text were then labelled with a code (second step). The data analysis was ongoing throughout data collection, this allowed modification of the interview guide to focus on emerging patterns. The identifying and coding of meaningful units was repeatedly re-evaluated, and earlier transcripts were recoded to reflect new codes. Towards the 21st interview, new data repeated what participants expressed in previous interviews and no new codes were emerging. We continued data collection for two more interviews to ensure and confirm that there were no new codes emerging. At this point, we concluded that data saturation was reached. All the coded units were grouped into themes and underlying subthemes by a 'comprehensive understanding' of how to interpret the findings in relation to the everyday experience of carers (third step). This understanding was achieved using a circular process (ie, a hermeneutic circle) that involved moving from the whole (naïve understanding) to the individual parts (structural analysis) and from the individual parts back to the whole 
(themes). The authors then used carers' own words with an understanding of the context (relationships, caring tasks, living arrangements, etc) to illustrate themes that retained the voice of the carers' personal experience and perspective.

Reflexivity ${ }^{43}$ and integrity of the research process was maintained by all three authors. The authors' experience as an occupational therapist (VS) and health services researchers $(\mathrm{CJ}$ and $\mathrm{MP})$, including research with people with long-term conditions, such as dementia, and their carers provided expertise necessary for this research. The authors had completed a systematic review on this research topic prior to the commencement of interviews, the interview topic guide was informed by the results of this review and there was active participation from the participants in the interviews, all of which assisted with triangulation. The authors' experience enables them to conduct a qualitative study of this nature. However, it is acknowledged that this experience may have influenced the coding and interpretation of the themes. VS conducted all the interviews and analysis, MP and CJ read selected transcriptions and coded meaning units and themes. The authors met regularly to discuss and agree data collection, analyses and interpretation.

\section{RESULTS}

\section{Participant characteristics}

Emails (n=387) for recruitment were sent to volunteers. From the responses received $(n=112), 61$ carers did not meet the eligibility criteria and 23 carers (14 women and 9 men), with varying types of relationship to a person with dementia, finally took part in interviews. Every participant had used at least one AT device in the last 12 months. Participants were aged between 42 and 91 years. Table 1 provides further detail on participant characteristics.

Themes: analyses generated five major themes that reflected experience of using AT and the impact it has had on their everyday life. Table 2 provides details of the themes and subthemes from the analysis and illustrative quotes.

\section{Theme 1: providing care for a person with dementia while using AT}

Participants expressed a mixed picture of additional responsibilities because of caring for someone with dementia. Some of these caring responsibilities acted as a trigger for considering and using AT. Some of the non-spousal carers, moved either themselves or the person with dementia, to be geographically closer; where this was not possible there was a reliance on using remote monitoring AT. Other participants relied on increasing the number of physical visits to the person with dementia and used additional paid carers.

Caring role: participants were providing support with personal care; continence management; leisure, domestic, household and financial tasks and transport for essential appointments.
...So, I help her, so basically, with like really fundamental carer activity. So, literally like washing, cleaning, all the glamorous stuff and I provide company for her as well. I help her with watching media or organising things around the home; that sort of stuff... (participant 7 , son, not living with person with dementia).

The level of care provided, was for some participants dependent on other responsibilities. For example, children of persons with dementia had caring responsibilities for their own children. As one carer put it, they saw themselves as 'a sandwich generation'.

I suppose I'm a typical sandwich generation person; the combination of dealing with my own family('s) needs and knowing that I need to sort of check up on, sort out, shop, cook for my mum as well.... I feel like I have a third child (participant 6 , daughter, not living with person with dementia).

AT was used as an additional layer of support in providing care for someone with dementia. AT was used for support with personal care tasks, safety, orientation to date and time, leisure and social interaction and to improve safety and security (table 1 ).

Financial considerations in using AT: participants invariably made the decisions on purchasing and using the AT. In most cases, these decisions were made independently of the person with dementia. While some participants had access to pendant alarms from their local authority social services, most participants purchased AT devices themselves. The costs of the AT were considered to be expensive, with decisions to try a particular AT determined by the cost.

a particular application can be developed and promoted and looks sexy and relatively... you know, can be sold for a price; doesn't mean to say it's actually going to be much added value (participant 15, husband, living with person with dementia).

I don't know. It is an expensive thing to experiment with.... Do I buy that?' even though it's maybe another hundred pounds. I can imagine that being a tough decision (participant 5, daughter, not living with person with dementia).

Participants also expressed concern that slightly modified AT were being marketed at a higher price simply because they were aimed at people with dementia who are likely to require the use of AT.

You know, the clock (Dementia clock) that I bought her; this clock that's got Monday to Friday on it, cost me fifty pounds. And if it's just a normal clock which normally would probably cost a tenner if it's for you and me (participant 10, daughter, not living with person with dementia).

Unanticipated issues from using AT: participants decided to use AT for reassurance and for providing additional support for the person with dementia, however, 

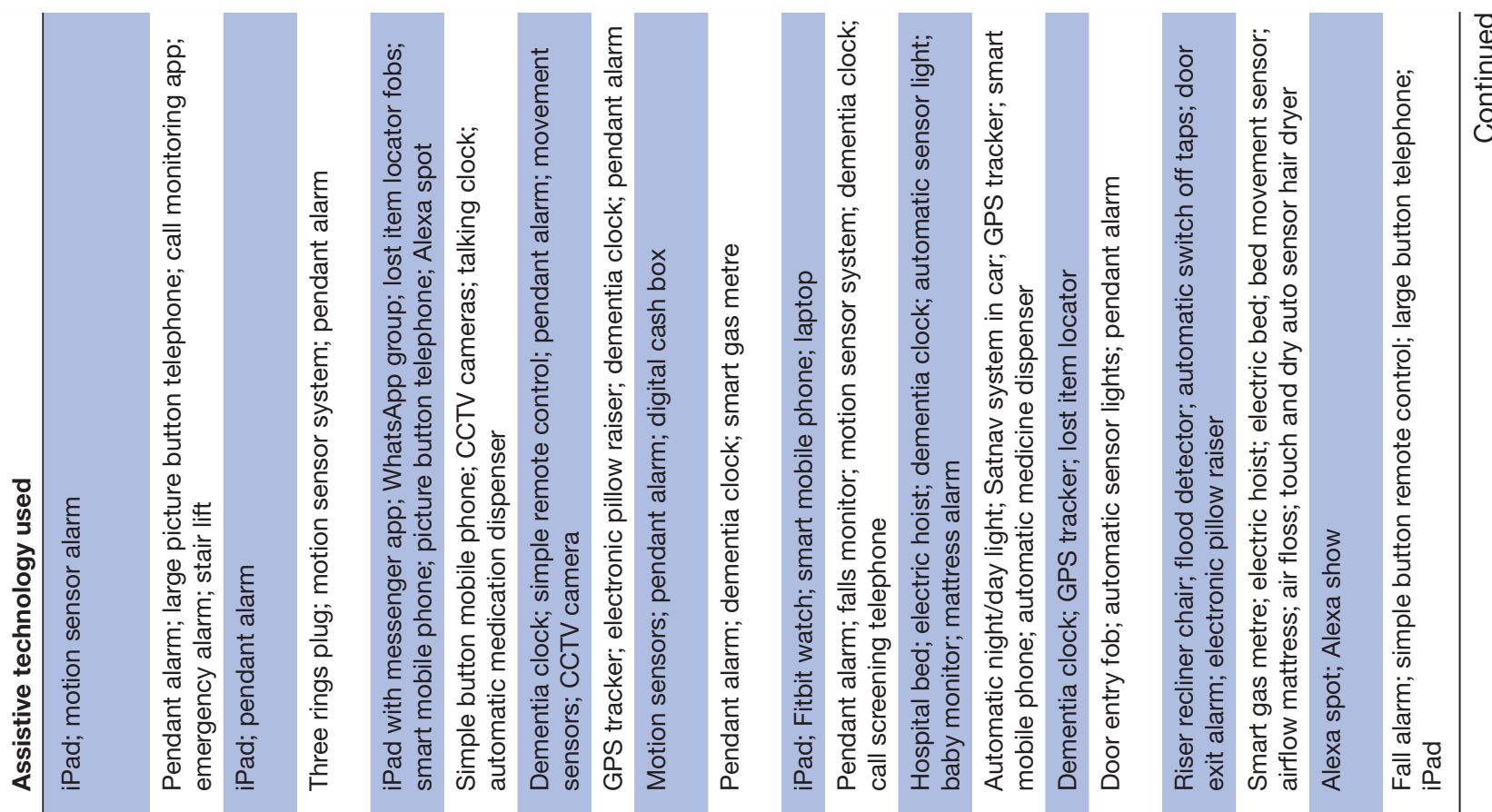

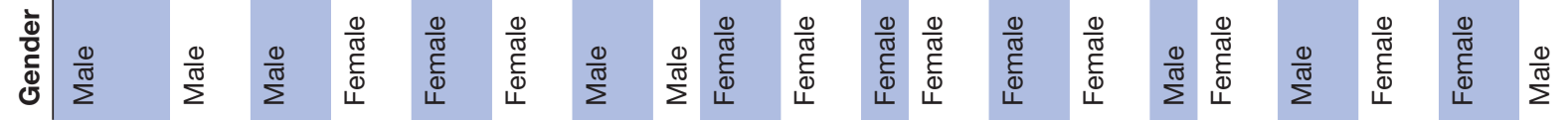

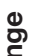


occasionally there were incidences where the AT failed or led to increased inconvenience for the carer.

...it (movement sensor) alerted me in the night. It also alerted me if a spider walked across, which wasn't ideal (participant 13, daughter, live-in carer).

when they changed the bed mattress (air-flow mattress), I couldn't really get it to work anyway with this alternating mattress because every time the cycle went round it set off the alarm because it thought there'd been an epileptic fit happening (participant 18 , daughter, live-in carer).

Occasionally, the AT could also assist a carer in other ways than it was intended for, which helped them provide a better level of care for a person with dementia.

Although it (a movement sensor system with remote alerts) wasn't set up to check-up on them (paid carers) in any way. We did find that a couple of the carers were saying that they had done things and with writing them in mum's record book. Yes, we found that one carer who was saying she was bathing mum but the monitors showing that nobody's been upstairs to the bathroom (participant 4, daughter, not living with person with dementia).

\section{Theme 2: motivation for using AT}

Carers had different reasons why they considered using AT. The initial motivator seemed to be wanting to problem solve for concerns or issues that the person with dementia was having. This included considerations of safety for the person with dementia, reassurance for carers and ease of use of a particular AT.

Freedom and autonomy: one reason articulated by participants for using AT was the freedom and autonomy that the AT devices provided to someone with dementia and the resultant additional freedom that it gave to the carers themselves to carry out other tasks.

I mean to the extent that they (simple remote control, dementia clock, movement sensors) put a possibly (sic) enough to keep her in her home and they might be critical to that actually, thinking about it (participant 7 , son, not living with person with dementia).

I mean if there's a film on it (iPad) he likes to watch, then I can get on if I'm here and not at work; I can get on with chores like ironing or doing something (participant 22, wife, living with person with dementia).

Quality of life and well-being: carers surprisingly did not express a desire for their own improved quality of life or well-being as a reason for choosing AT; however, reasons for reassurance of the safety and welfare of the person with dementia was mentioned often. Once the AT was in place, carers were able to appreciate the positive influence on their well-being, and this did vary over time depending on the progressive nature of dementia. 


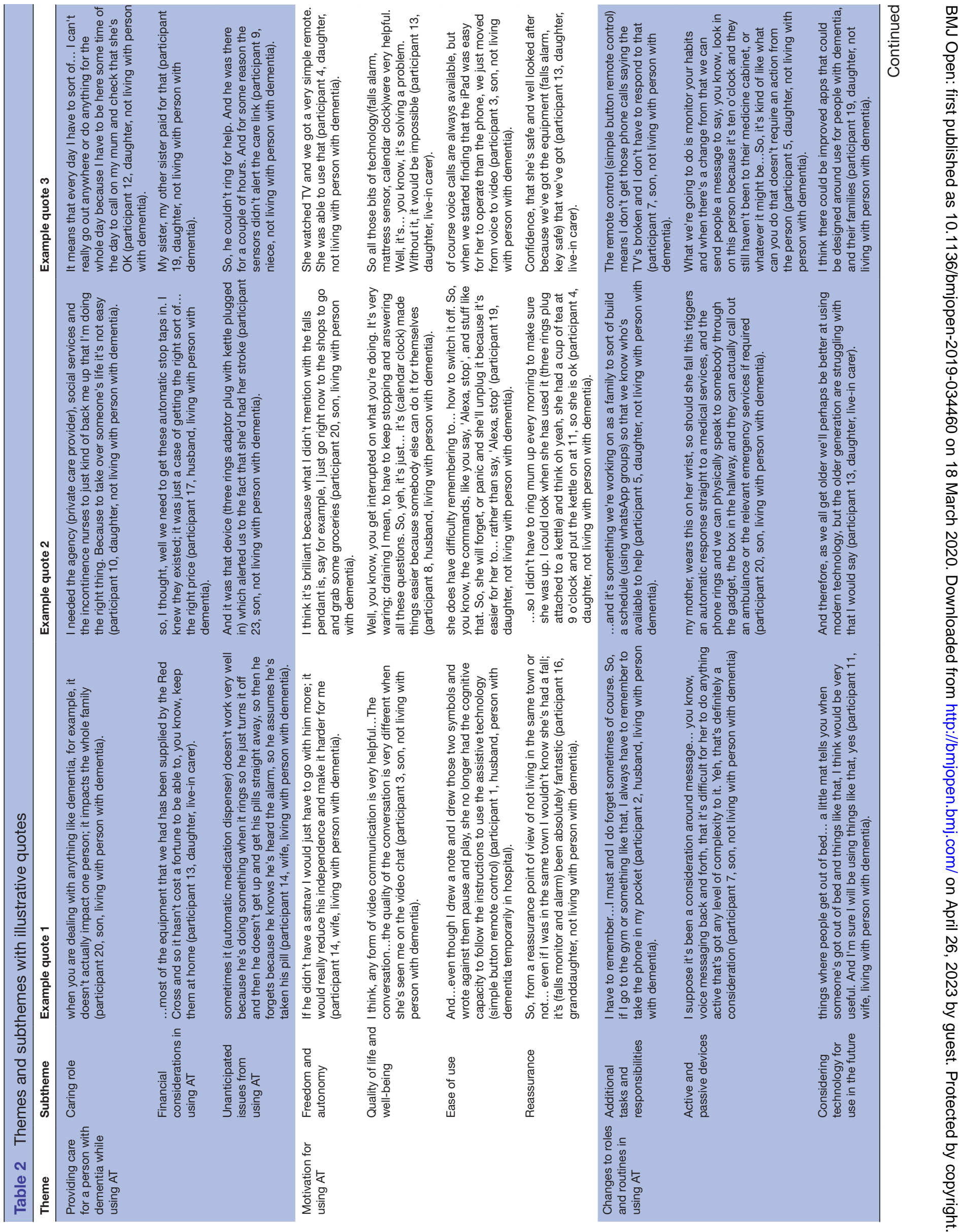




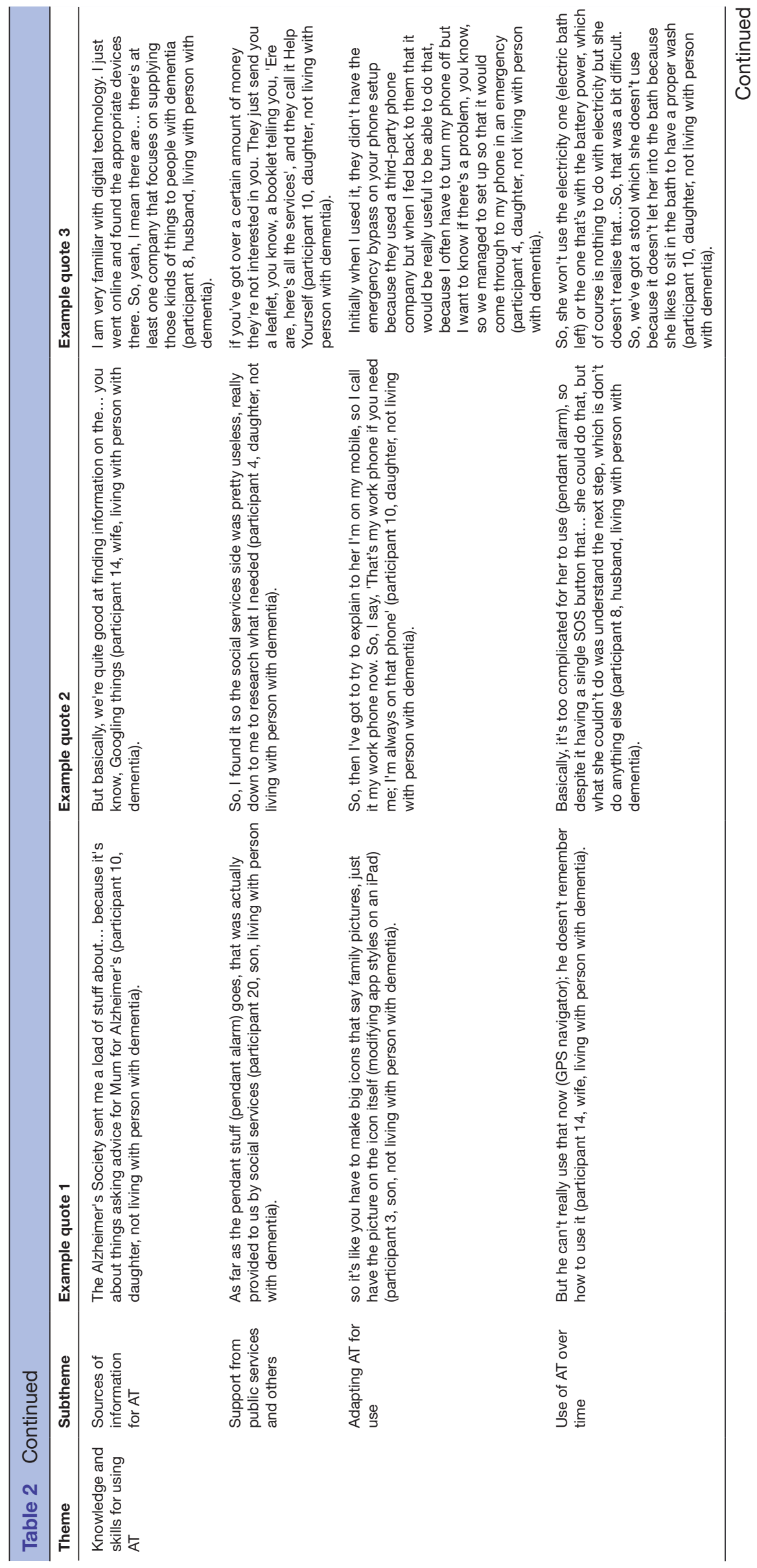




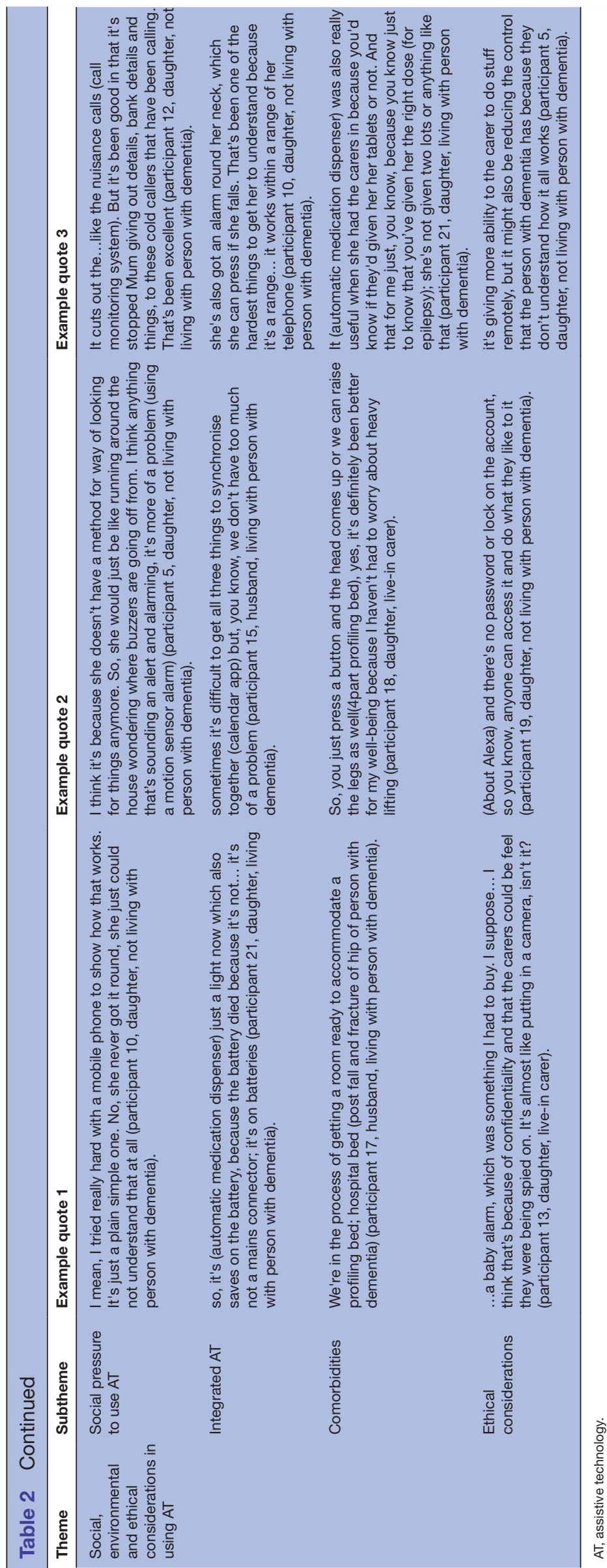


she was on the phone constantly day and night ringing up to see what day it was, what time it was; what was she supposed to be doing at that time. Well we don't get that anymore because she just looks at the clock (Dementia Clock) and she knows. So yes, definitely it's cut my workload, if you like, down a lot (participant 12, daughter, not living with person with dementia).

I think it's (wrist fall alarm, simple button remote, large button telephone, iPad) absolutely been a life changer for me as a carer, for me as a son, and as a family member as well (participant 20, son, living with person with dementia).

Occasionally, the increased anxiety over safety, especially for a carer who lived further away from the person with dementia, resulted in overuse of AT that exacerbated their need for constant reassurance of the welfare of the person with dementia.

My husband used to worry that, I was checking too much (participant using motion sensors in the home of person with dementia that could be viewed on a smart phone). Say I didn't switch off (participant 4, daughter, not living with person with dementia).

Ease of use: there were positive and negative views on how easy it is for a person with dementia or for the carer to use an AT device. Even though this was a factor that was considered before purchase of an AT device, it was only after it was purchased and trialled at home that some of the issues on ease of using it surfaced.

He hears the phone (smart phone) ringing (video call). He realises it's me because nobody else phones him because he never switches it on. And he'll come indoors to see what I want rather than pick it up and answer it because I'm not sure he knows how to do it (participant 11, wife, living with person with dementia).

....also, it's an easy phone to use (picture button telephone). So, if (person with dementia) wanted to dial out, err...she presses the A button, and she presses that (points to his picture on the phone) and she talks. Anyway, it's a nice bit of kit that (participant 2, husband, living with person with dementia).

Reassurance: for many participants, the use of AT provided a useful additional layer of reassurance for the care of a person with dementia, even if it was technology that was rarely used.

when we had the sensors on (motion sensor system), that was the most helpful for me because it was a real peace of mind knowing that she was moving about from room to room and that, you know, obviously then she was fine (participant 12, daughter, not living with person with dementia).

And it's sort of like an extra level of reassurance. But I mean because she was wandering, so it is kind of good to know that there's a thing there (door exit alarm). I don't know... yeah, it's not really been used but it's sort of good to have, so yeah (participant 21, daughter, living with person with dementia).

Participants who lived further away, consistently expressed the need to have reassurance that the person with dementia was safe, even if they did not need physical help or prompting. These check-visits by professional carers were not available from public services and carers instead relied on remote monitoring systems.

\section{Theme 3: changes to roles and routines}

Participants frequently referred to a range of lifestyle adjustments in caring for a person with dementia and this extended to using AT.

Additional tasks and responsibilities: the use of AT meant the carers had to take on additional responsibilities and adjust their routines. Carers did not consider this an onerous change and the benefits that the AT provided appeared to outweigh these additional tasks and changes to routines.

He likes me to set it (GPS satellite navigation system for use in car and for walks) for him now. I don't know whether he's... that's because... I think that's because he's had problems setting it himself (participant 14, wife, living with person with dementia).

it's almost second nature now just to have a quick check on the motion sensors and a quick check on her location (participant 23, son, not living with person with dementia).

Active and passive devices: participants expressed a wish to use devices that actively anticipated the needs of a person with dementia as they felt that cognitive decline in someone with dementia usually necessitated devices that could predict and react to what the person with dementia wanted. At the time of the interview, none of the carers used an artificial intelligence-driven device that could provide this function.

...but for my wife and her particular presentation of the dementia, any assistive technology would have been, has to be absolutely passive and require no input whatsoever from her (participant 1, husband, person with dementia temporarily in hospital).

It has to be something passive. Passive sensors or even understanding in our absence from a location perspective, where is she... and how often is she...so, in those kinds of situations when somebody is alone, what would be (sic) those passive sensors that actually come alive and create a real time alert for the caregivers (participant 3, son, not living with person with dementia).

Participants also had to modify/change AT when a device that required active engagement from the person with dementia was no longer considered adequate. A frequent issue raised by carers was regarding the pendant alarms that were issued to persons with dementia by social services, 
to alert a carer or a call centre. More often than not, the person with dementia was not aware of how to use the pendant alarm when required. Consequently, some participants indicated that they used a falls alarm that triggered an automatic alert to a call centre.

Mum (now) has a falls monitor that she wears round her neck. We did have a standard call alarm that you press a button or a pendant round her neck, but Mum had a couple of falls and had no idea what this thing round her neck was for (participant 12, daughter, not living with person with dementia).

Yes, he has the pendant alarm but sometimes he forgets to... you know, he forgets about it (participant 9, niece, not living with person with dementia).

Considering technology for use in the future: carers felt that the younger generation was getting better at using technology and the use of AT for caring for someone with dementia was likely to increase in the future. In addition to currently using AT, carers also had to anticipate future problems that the person with dementia could have and how to support them.

I could get sensors in and I could see what she's doing. And I could also put something on her front door which would enable me to see who's... you know, use that app that's come out where you can see, well who's actually getting into the house and stop them getting in (participant 10, daughter, not living with person with dementia).

I will get some sort of tracker thing with his agreement so that when he gets lost, if he gets lost when we're on holiday, we're going out for a walk or something and somehow we've got separated and we'll be able to find each other (participant 14, wife, living with person with dementia).

\section{Theme 4: knowledge and skills for using AT}

Participants used a variety of sources to find out about what help/support they could get for a person with dementia. Personal knowledge, shared knowledge from other family members, support groups, public and third sector organisations as well as internet searches helped carers find out and keep themselves updated about AT. Carers also had to rely on their skills to adapt and adopt AT for use by someone with dementia.

Sources of information for AT: all of the carers interviewed reported using dementia specific charities as a source of information on AT. Information was gathered either by the main carer or a family member from websites and through involvement in local dementia or carer support groups.

I belong to a carers group in (name of town) and we have had a couple of presentations from people who have come along to tell the carers about technology, which is available (participant 1, husband, person with dementia temporarily in hospital).
(National Charity) were quite good and they have some quite good websites, and so I did quite a lot of reading beforehand and also dementia (town) and (they) have leaflets and stuff (participant 4, daughter, not living with person with dementia).

Support from public services and others: the AT products themselves were overwhelmingly purchased by private contributions with some AT devices such as pendant alarms and hospital beds being provided or suggested through health or social care services.

(I) think they were all items that were suggested by somebody as a result of health specialists in some way...they came up with the calendar...clock/calendar thing, and they were quite proactive in coming up with various things (participant 13, daughter, livein carer).

The emergency pendant, the social workers there were very good and suggested things like that. The TV remote control, we saw that at meeting at a local charity near us that has a meeting for people with young onset dementia (participant 14, wife, living with person with dementia).

However, support from public services was not always satisfactory, as providing just information was not sufficient for some carers.

it takes a bit of imagination and confidence to find the help that you need (from local council). I think it's really difficult for people. But I think an awful lot of people don't and have to... and kind of give up in desperation and people end up in care homes and then everybody's unhappy (participant 13, daughter, live-in carer).

Adapting AT for use. Some of the AT had to be adapted for successful use. This depended in part on the skill and confidence (sometimes trial and error) of the carer in enabling this to happen and for others in changing routines or adapting the physical environment so that the AT could be effective.

...the reason for that is, is that bit on here (points to the pendant button and elevated ring around it) is not part of the original kit. It's something I have put on it...the button protrudes, well as you can imagine, the minute you put it on, brush your hand against it, it goes off. So, I went and bought a piece of...I think it was a piece of plumbing fitting. Cut the end of it and glued it onto there, so that you have to...press it (participant 2, husband, living with person with dementia).

Having the app (connected to movement sensors) was brilliant. I think if you had to find a laptop and logging and all that, it would have been a bind. I think the fact that most people have smartphones and you just do that and it's like $30 \mathrm{~s}$, you know you've got all 
the information you need (participant 4, daughter, not living with person with dementia).

Use of AT over time. the unpredictable and progressive nature of dementia meant that a person with dementia's ability to use an AT device changed over time, occasionally leading to new devices being tried or more often AT being abandoned. This meant carers having to be aware of and constantly looking for additional information on AT.

We had little monitors set up round the house that could tell where she was moving and when she'd gone into the kitchen and we could access it from our iPads and see what she was doing. We only (had) that for a short period of time... But it was really valuable when we did have it (participant 12, daughter, not living with person with dementia).

it can be a bit discouraging as well when you, you know, keep buying new stuff and then it gets kind of put to one side. It's just trial and error (participant 5, daughter, not living with person with dementia).

\section{Theme 5: social, environmental and ethical considerations}

Dementia like any other long-term condition can be viewed from a biopsychosocial model. AT use by and for people with dementia is also linked to the social and environment context of use. These include attitudes towards technology by the carers and persons with dementia, technology systems that are integrated into everyday care, social structures including age, gender, experience of using technology and coping styles.

Social pressure to use AT: caring for a person with dementia might introduce pressures on carers to buy or provide care that they would not choose by themselves but because of peer pressure or wanting to be seen as doing the right thing for the person with dementia.

whenever you go to see the doctors or you see the mental health team or... and they all say to you, 'Has she got this, has she got that, has she got... do that, has she done this?' And you think to yourself, 'Well, I'd better have it then because it's obviously something that people think they're useful'. So, to a certain extent she has the (pendant) alarm because everyone expected to have the alarm because she (is) older (participant 10, daughter, not living with person with dementia).

(I bought) a baby alarm, which was something I had to buy. I suppose... I think that's because of confidentiality and that the (professional) carers could be feel (sic) they were being spied on (by putting in a camera), isn't it? (participant 13, daughter, live-in carer).

Integrated AT: the provision and use of AT does not happen in vacuum, most AT devices need the support of other technology solutions to be available to work in the intended manner and occasionally these were unavailable or had additional cost implications. Carers also had to use multiple AT devices in isolation as they were manufactured by different providers and did not integrate and work well together.

I'm also a little bit worried...I'm very concerned that a lot of stuff (movement sensors) are wireless route (sic). Well, that concerns me a little bit because if there's a breakdown in the internet, which (rural community in Scotland) is a bit renown for (participant 16, granddaughter, not living with person with dementia).

...the sense of longevity and also the entire patient journey, that same piece of equipment does not solve the problem and they are not integrated. There are very discrete pieces, but they are not matching with disease progression as they only solve one problem at a time and do not match up to condition that progresses (participant 3, son, not living with person with dementia).

Comorbidities: dementia and the use of AT by carers in the care of persons with dementia was the main focus of this study. The interviews revealed that carers were having to make decisions for someone who had multiple comorbidities. AT use in these circumstances was reduced and additional formal carers were employed, or AT was purchased to support issues other than those related to dementia.

That's made it... I wouldn't say more difficult, but it's changed the nature (of care). In fact, to be honest, in some ways it's (i.e. the person with dementia having a stroke) made it easier because we now have carers coming in twice a day as well (participant 23, son, not living with person with dementia).

She's got a pillow lifter. Because of the extreme arthritis in her shoulder she has this pillow lifter that can raise up or down...the other arm... because of the extreme arthritis in the shoulder is... she can't really put much strength on it you see...pillow lifter handset, she has to be prompted to use them (participant 17 , husband, living with person with dementia).

Ethical considerations: decisions regarding purchase and use of AT did not always involve the person with dementia. Participants did actively reflect on ethical issues when using AT that could be seen as being intrusive, especially those that allowed remote monitoring.

We stopped having it (movement sensors in every room) because I felt it was an infringement of her privacy. I felt quite awkward about it, so we didn't have it anymore (participant 12, daughter, not living with person with dementia).

We have (had) been thinking of putting cameras in our house for security purposes, but we have not yet done that. I don't think she'll have a problem with that at all...but We don't have a camera and we decided not to use it (participant 3, son, not living with dementia). 
Even if a person with dementia initially consented to use of intrusive/privacy-reducing technology at home, it was not followed up over time, especially when the condition of the person with dementia deteriorated. Carers did consider issues of privacy, dignity and beneficence and non-malfeasance; however, these considerations were often supplanted by safety, vulnerability and autonomy of the person with dementia.

We don't... there's nothing observing what she's up to in the bathroom or in the bedroom, but we can see that she's up and moving around, so that is very useful (participant 6, daughter, not living with person with dementia).

Carers also chose not to use certain types of AT as they felt it would further isolate a person with dementia.

it (remote video monitoring) might give people an excuse to do less and less talking and less and less face to face, and I know that's, for her, is definitely one of the things that brings her most happiness and joy, is actually the human stuff (participant 7, Son, Not living with person with dementia).

A couple of participants also expressed concerns of third-party data sharing and potential hacking into private devices.

We put a very strong password on and all that kind of thing, but we saw these... well, I saw these websites where they had photographs of people on webcams, ladies in beds and things and a little bit worrying really when you think someone might be hacking in and looking at your Mum (participant 18, daughter, livein carer).

Yeh, it's the technology. There's all this thing, 'Oh, it's listening into everything we say' (speaking about concerns from other family members on using Alexa-a cloud-based voice service)' (participant 19, daughter, not living with person with dementia).

\section{DISCUSSION}

This study explored experiences of current users of AT in dementia care at home. It explored the experience of carers using AT who are resident in the UK, but the issues discussed will have a resonance for carers across the world in similar situations.

A majority of the participants expressed a positive experience in the use of AT. As in other research, ${ }^{1944} 45$ ease of use, providing a sense of reassurance, considerations of safety and autonomy were all reasons for carers to consider using AT. Similar to other reports on caring for an elderly population in the community, ${ }^{23}$ we found that carers continued to use AT regardless of having an increase in formal care services or having to find information and fund the purchase of the AT themselves. AT appeared to complement carer support by redeployment of carer time to more meaningful activities and interactions with the person with dementia. Carers generally consider AT as helping the person with dementia and when prompted are able to consider the impact on their own quality of life and well-being. ${ }^{47}$

Carers were troubled by the cost implications of testing new AT devices, especially as dementia progresses; and this appears to be a neglected area in research and policy. ${ }^{13} 16$ This study took place in the UK, where health services for individuals are provided free at the point of use, but AT is provided through social care services which is means tested and restricted to those with substantial needs and the least assets. Infact only about $25 \%$ of the people applying for social care actually get it ${ }^{48}$ and most persons with dementia may not qualify. ${ }^{49}$ AT use in dementia is not a one-off event, it is an ongoing process, ${ }^{14}$ having a repository of AT devices that carers could borrow, trial and return when the AT is no longer useful for a person with dementia may help overcome some of the concerns of carers and reduce waste and re-use of resources. The use of pendant alarms issued by social services was one common example, where the AT was not keeping pace with the progress of dementia; the person with dementia no longer able to actively use the device leading to the abandonment of the AT. ${ }^{50} 51$

Other studies on AT have reported on carers modifying existing AT devices for newer purposes ${ }^{22} 26$ or using AT devices for comorbidities ${ }^{52}$ not associated with dementia, this was not possible for all carers and care situations among the participants in this study. The dynamic nature of progress of an illness such as dementia, the context and environment in which AT is being used and the motivation for using AT, necessitates viewing AT use for supporting carers and persons with dementia from a dynamic biopsychosocial model for health. ${ }^{53}$ Results from this study support this view.

Carers who lived away from the person with dementia, expressed the need for a 'check-in' for reassurance that someone with dementia was safe and well ${ }^{54}{ }^{55}$ and there was a worry among some carers that the reliance and use of AT may usurp the need for human interaction and worsen social isolation. ${ }^{56}{ }^{57}$ Similar to other studies on $\mathrm{AT}^{455859}$ carers, while considering the wishes of the person with dementia when selecting AT solutions, did make independent decisions to preserve their safety and security. ${ }^{60-62}$ While intrusive data sharing and data loss were not concerning for a majority of the carers, some have started expressing concerns with integrated AT and this is likely to require further research and policy intervention as AT devices will become increasingly sophisticated, available on the 'cloud' and artificial intelligence driven. ${ }^{4763}$

\section{Strengths and limitations of this study}

This study looked at AT use among carers of persons with dementia. Drawing on participants from across the UK ensured that geographical limitations of procuring and using AT did not limit the transferability of our findings. The interviews used open-ended questions and the researchers were not known to the participants and ongoing data analysis showed that satisfactory data saturation was achieved. We aimed to recruit carers from different ethnic backgrounds 
but as participation in the interviews was voluntary and only English language speakers were included in the study, this could not be fully achieved.

\section{Research and policy suggestions}

The findings reported in this study suggest further research is needed on how AT such as pendant alarms are being used by persons with dementia, as their condition progresses. This is especially important in light of additional demands that may be placed on carers with the use of such devices. ${ }^{6465}$ Healthcare professionals should consider use of other 'passive devices' that could be more beneficial to persons with dementia and their carers. From a policy perspective, consideration should be given to the establishment of a community based AT store/bank for use by persons with long-term conditions, including dementia; this can recycle and reuse AT devices in the community to help reduce the burden of cost and trial and error of purchasing AT for persons with dementia, as their condition progresses. There should be evidence-based policies with input from healthcare workers, academics, industry partners, persons with dementia and their carers on proxy decision making for AT use, data sharing and data donation from use of AT. Active policy interventions to address emerging data protection concerns of carers when using AT should also be considered.

\section{CONCLUSION}

AT can play an important role in supporting carers and persons with dementia and is seen as an adjunct to care. Previous research has considered experience of using particular AT devices or experience of AT use mainly from the perspective of person with dementia. This study has examined experience of AT use in the community from the perspective of carers and without restriction on the type or amount of AT being used. This study highlights important gaps in the understanding of experiences of AT use in dementia care in the community. AT research, practical use and policy solutions should follow a biopsychosocial model that considers the appropriate use of AT in individual and social contexts. While AT can provide support that is less intrusive, provides reassurance and improves well-being of carers, there continue to be issues that need to be addressed around ethical considerations in the use of AT, costs involved and additional tasks and role changes that carers need to accommodate while providing care for a person with dementia.

\section{Twitter Vimal Sriram @vimalsrir}

Acknowledgements The authors would like to thank the three members of the patient and public engagement and involvement panel set up as part of the carers' experience of assistive technology use in dementia study, for their comments on the interview questions and findings. The authors would like to acknowledge the contributions of all the participants in this study for their time and invaluable insight into the use of AT. The authors also acknowledge the constructive comments from the reviewers which have helped clarify, refine and strengthen this manuscript.

Contributors VS, CJ and MP conceived the design of the study. VS completed the interviews and transcribed the audio recordings with support from a professional transcriber. VS, MP and CJ analysed the transcripts and discussed emerging themes and agreed final theme creation. VS drafted this version of the manuscript with critical revision and input from MP and CJ. All authors have read and given approval for this version. VS is the guarantor of the manuscript.

Funding This research is part of a DPhil in Population Health at the University of Oxford and received no specific grant from any funding agency in the public, commercial or not-for-profit sectors.

Competing interests None declared.

Patient and public involvement Patients and/or the public were involved in the design, conduct, reporting or dissemination plans of this research. Refer to the 'Methods' section for further details.

Patient consent for publication Not required.

Ethics approval This study was approved by the University of Oxford Central University Research Ethics Committee (reference number: R57703/RE001).

Provenance and peer review Not commissioned; externally peer reviewed.

Data availability statement Data are available in a public, open access repository. Extra data from anonymised transcripts are available from the DRYAD repository at: Sriram, Vimal; Jenkinson, Crispin; Peters, Michele (2019), Carers' experience of using assistive technology for dementia care at home: a qualitative study, Dryad, Dataset, https://doi.org/10.5061/dryad.kd51c5b23.

Open access This is an open access article distributed in accordance with the Creative Commons Attribution Non Commercial (CC BY-NC 4.0) license, which permits others to distribute, remix, adapt, build upon this work non-commercially, and license their derivative works on different terms, provided the original work is properly cited, appropriate credit is given, any changes made indicated, and the use is non-commercial. See: http://creativecommons.org/licenses/by-nc/4.0/.

ORCID iD

Vimal Sriram http://orcid.org/0000-0003-2139-8591

\section{REFERENCES}

1 WHO, World Health Organization. Dementia: a public health priority. Geneva: World Health Organization, 2012. http://www.who.int/ mental_health/publications/dementia_report_2012/en/

2 Department of Health. G8 dementia Summit declaration. G8 heal. SCl. Minist. Declar, 2013. Available: https://www.gov.uk/government/ uploads/system/uploads/attachment_data/file/265869/2901668_G8_ DementiaSummitDeclaration_acc.pdf [Accessed 1 Dec 2017].

3 Prince M, Knapp M, Guerchet M, et al. Dementia UK: update 2014.

4 World Health Organisation. Dementia. key facts. world heal. organ. key facts, 2017. Available: http://www.who.int/news-room/factsheets/detail/dementia [Accessed 30 Aug 2018].

5 Oyebode JR, Pini S, Ingleson E, et al. Development of an item pool for a needs-based measure of quality of life of carers of a family member with dementia. Patient 2019;12:125-36.

6 Lewis F, Karlsberg Schaffer S, Sussex J, et al. The Trajectory of Dementia in the UK - Making a Difference. London, 2014. https:// www.ohe.org/publications/trajectory-dementia-uk-makingdifference\#

7 Luengo-Fernandez R, Leal J, Gray A. The economic burden of dementia and associated research funding in the United Kingdom. Cambridge, 2010. www.dementia2010.org

8 The Lancet. Addressing global dementia. Lancet 2014;383:2185.

9 Beesley L. Informal care in England Derek Wanless social care review background paper 2006, 2006. Available: https://www.kingsfund.org. uk/sites/default/files/informal-care-england-wanless-backgroundpaper-lucinda-beesley2006.pdf [Accessed 24 Jun 2019].

10 Clare L, Nelis SM, Martyr A, et al. The influence of psychological, social and contextual factors on the expression and measurement of awareness in early-stage dementia: testing a biopsychosocial model. Int J Geriatr Psychiatry 2012;27:167-77.

11 Borrell-Carrió F, Suchman AL, Epstein RM. The biopsychosocial model 25 years later: principles, practice, and scientific inquiry. Ann Fam Med 2004;2:576-82.

12 Spector A, Orrell M. Using a biopsychosocial model of dementia as a tool to guide clinical practice. Int Psychogeriatr 2010;22:957-65.

13 Daly Lynn J, Rondón-Sulbarán J, Quinn E, et al. A systematic review of electronic assistive technology within supporting living environments for people with dementia. Dementia 2019;18:2371-435.

14 Woolham J, Gibson G, Clarke P. Assistive technology, Telecare, and dementia: some implications of current policies and guidance. Res 
Policy Plan 2006;24:149-64 http://ssrg.org.uk/wp-content/uploads/ 2012/02/rpp243/p19p34.pdf

15 Gibson G, Newton L, Pritchard G, et al. The provision of assistive technology products and services for people with dementia in the United Kingdom. Dementia 2016;15:681-701.

16 Gibson G, Dickinson C, Brittain K, et al. The everyday use of assistive technology by people with dementia and their family carers: a qualitative study. BMC Geriatr 2015;15:89.

17 The Audit commission. Assistive technology. London, 2004. Available: http://www.wales.nhs.uk/documents/National20Report_ FINAL.pdf [Accessed 27 Nov 2017].

18 Department of Health and Social Care. Assistive technology research and development work: 2017 to 2018 - GOV. UK. London 2019 https:// www.gov.uk/government/publications/assistive-technology-researchand-development-work-2017-to-2018 (accessed 1 Mar 2019).

19 Sriram V, Jenkinson C, Peters M. Informal carers' experience of assistive technology use in dementia care at home: a systematic review. BMC Geriatr 2019;19:160.

20 Huschilt J, Clune L. The use of socially assistive robots for dementia care. J Gerontol Nurs 2012;38:15-19.

21 National Institute for Health Research. Internet of things being used in innovative dementia research. Natl. Inst. Heal. Res 2017.

22 Greenhalgh T, Wherton J, Sugarhood P, et al. What matters to older people with assisted living needs? A phenomenological analysis of the use and non-use of telehealth and telecare. Soc Sci Med 2013;93:86-94.

23 Wanless $\mathrm{D}$. Securing good care for older people: taking a longterm view. Wanless social care review, 2006. Available: https:// www.kingsfund.org.uk/sites/default/files/field/field_publication_file/ securing-good-care-for-older-people-wanless-2006.pdf [Accessed 2 Aug 2019].

24 Gubbi J, Buyya R, Marusic S, et al. Internet of things (IoT): a vision, architectural elements, and future directions. Future Generation Computer Systems 2013;29:1645-60.

25 NIHR Dissemination Centre. Help at Home - Use of assistive technology for older people. London 2018.

26 Gibson G, Dickinson C, Brittain K, et al. Personalisation, customisation and bricolage: how people with dementia and their families make assistive technology work for them. Ageing Soc 2018:1-18.

27 Sriram V, Jenkinson C, Peters M. Informal carers' experience and outcomes of assistive technology use in dementia care in the community: a systematic review protocol. Syst Rev 2019;8:158

28 Laverty SM, Phenomenology $\mathrm{H}$. Hermeneutic phenomenology and phenomenology: a comparison of historical and methodological considerations. Int J Qual Methods 2003;2:21-35.

29 Kakkori L. Hermeneutics and phenomenology problems when applying Hermeneutic phenomenological method in educational qualitative research. J Can Philos Educ Soc 2009;18:19-27.

30 Figal G. Hermeneutical phenomenology. Oxford, UK: Oxford University Press, 2012

31 Jentoft R, Holthe T, Arntzen C. The use of assistive technology in the everyday lives of young people living with dementia and their caregivers. Can a simple remote control make a difference? Int Psychogeriatrics 2014;26:2011-21.

32 Wallström S, Ulin K, Omerovic E, et al. Symptoms in patients with takotsubo syndrome: a qualitative interview study. BMJ Open 2016;6:e011820.

33 Tashakkori A, Teddlie C. Sage handbook of mixed methods in social \& behavioral research. SAGE Publications, 2010. https://uk.sagepub. com/en-gb/eur/sage-handbook-of-mixed-methods-in-socialbehavioral-research/book233405. (accessed 4 Dec 2017).

34 Thomas K, Gamlin C, De Simoni A, et al. How is poststroke fatigue understood by stroke survivors and carers? A thematic analysis of an online discussion forum. BMJ Open 2019;9:e028958.

35 Papi E, Murtagh GM, McGregor AH. Wearable technologies in osteoarthritis: a qualitative study of clinicians' preferences. BMJ Open 2016;6:e009544.

36 Braun V, Clarke V. Using thematic analysis in psychology. Qual Res Psychol 2006;3:77-101.

37 Lindseth A, Norberg A. A phenomenological hermeneutical method for researching lived experience. Scand J Caring Sci 2004;18:145-53.

38 Di Tommaso A, Wicks A, Scarvell J, et al. Experiences of occupationbased practice: an Australian phenomenological study of recently graduated occupational therapists. British Journal of Occupational Therapy 2019;82:412-21.

39 Starks H, Trinidad SB. Choose your method: a comparison of phenomenology, discourse analysis, and grounded theory. Qual Health Res 2007;17:1372-80.
40 Tong A, Sainsbury P, Craig J. Consolidated criteria for reporting qualitative research (COREQ): a 32-item checklist for interviews and focus groups. Int J Qual Health Care 2007;19:349-57.

41 National Institute of Health Research,, Alzhemier's Society. Join dementia research, 2019. Available: https://www. joindementiaresearch.nihr.ac.uk/home?login [Accessed $2 \mathrm{Jul}$ 2019].

42 NIHR Oxford BRC. Oxford dementia and ageing research (OxDARE), 2019. Available: https://www.oxdare.ox.ac.uk/home [Accessed 2 Jul 2019].

43 Etherington K. Becoming a Reflexive Researcher - Using Our Selves in Research. London: Jessica Kingsley, 2004.

44 Lorenz K, Freddolino PP, Comas-Herrera A, et al. TechnologyBased tools and services for people with dementia and carers: mapping technology onto the dementia care pathway. Dementia 2019;18:725-41.

45 Rialle V, Ollivet C, Guigui C, et al. What do family caregivers of Alzheimer's disease patients desire in smart home technologies? contrasted results of a wide survey. Methods Inf Med 2008;47:63-9.

46 Ward G, Fielden S, Muir H, et al. Developing the assistive technology consumer market for people aged 50-70. Ageing Soc 2017;37:1050-67.

47 Wang RH, Sudhama A, Begum M, et al. Robots to assist daily activities: views of older adults with Alzheimer's disease and their caregivers. Int. Psychogeriatr. 2017;29:67-79.

48 The King's Fund. Key facts and figures about adult social care, 2019. Available: https://www.kingsfund.org.uk/audio-video/key-factsfigures-adult-social-care [Accessed 14 Jan 2020].

49 Hutchings R, Carter D, Bennette K. Dementia-the true cost: fixing the care crisis. London, 2018. Available: https://www.alzheimers.org. uk/sites/default/files/2018-05/Dementia the true cost - Alzheimers Society report.pdf [Accessed 14 Jan 2020].

50 May CR. Making sense of technology adoption in healthcare: mesolevel considerations. BMC Med 2015;13:92.

51 Greenhalgh T, Procter R, Wherton J, et al. What is quality in assisted living technology? the ARCHIE framework for effective telehealth and telecare services. BMC Med 2015;13:91.

52 Bunn F, Burn A-M, Goodman C, et al. Comorbidity and dementia: a scoping review of the literature. BMC Med 2014;12:192.

53 Lehman BJ, David DM, Gruber JA. Rethinking the biopsychosocial model of health: understanding health as a dynamic system. Soc Personal Psychol Compass 2017:11:e12328.

54 Bledsoe LK, Moore SE, Collins WL, et al. Long distance caregiving: an Evaluative review of the literature context for provision of care from a distance. Ageing Int 2010;35:293-310.

55 Czaja SJ, Rubert MP. Telecommunications technology as an aid to family caregivers of persons with dementia. Psychosom Med 2002:64:469-76.

56 Powell J, Gunn LEE, Lowe PAM, et al. New networked technologies and carers of people with dementia: an interview study. Ageing Soc 2010;30:1073-88.

57 Zucchella C, Sinforiani E, Tamburin S, et al. The multidisciplinary approach to Alzheimer's disease and dementia. A narrative review of non-pharmacological treatment. Front Neurol 2018;9:1058.

58 Powell J, Chiu T, Eysenbach G. A systematic review of networked technologies supporting carers of people with dementia. J Telemed Telecare 2008;14:154-6.

59 Rosenberg L, Nygård L, Nygard L. Persons with dementia become users of assistive technology: a study of the process. Dementia 2012;11:135-54

60 Essén A. The two facets of electronic care surveillance: an exploration of the views of older people who live with monitoring devices. Soc Sci Med 2008;67:128-36.

61 Hanson J, Percival J, Aldred H, et al. Attitudes to telecare among older people, professional care workers and informal carers: a preventative strategy or crisis management? Univ Access Inf Soc 2007:6:193-205.

62 Percival J, Hanson J. Big brother or brave new world? Telecare and its implications for older people's independence and social inclusion. Critical Social Policy 2006;26:888-909.

63 Boulos MNK, Wheeler S, Tavares C, et al. How smartphones are changing the face of mobile and participatory healthcare: an overview, with example from eCAALYX. Biomed Eng Online 2011;10:24

64 Milligan C, Roberts C, Mort M. Telecare and older people: who cares where? Soc Sci Med 2011;72:347-54.

65 Spring HJ, Rowe MA, Kelly A. Improving caregivers' well-being by using technology to manage nighttime activity in persons with dementia. Res Gerontol Nurs 2009;2:39-48. 